\title{
SEISMIC PERFORMANCE OF A BLOCK OF BUILDINGS REPRESENTATIVE OF THE TYPICAL CONSTRUCTION IN THE EIXAMPLE DISTRICT IN BARCELONA (SPAIN)
}

\author{
Pujades $^{(1,3)}$ L.G., Barbat ${ }^{(1)}$ A.H., González-Drigo ${ }^{(1)}$ R., Avila ${ }^{(1)}$ J. and S. Lagomarsino ${ }^{(2)}$ \\ (1) Universidad Politécnica de Cataluña, Barcelona, Spain \\ ${ }^{(2)}$ Università degli Studi di Genova, Genova, Italia \\ ${ }^{(3)}$ Corresponding author: email::lluis.pujades@upc.edu, tel. +34 934017258,fax: +34 934017251.
}

\begin{abstract}
Between the late nineteenth century and the early twentieth century, Barcelona was expanded, occupying the terrains connecting the old walled city and the nearby towns of the plateau of Barcelona. At that time, a large number of unreinforced masonry buildings were constructed and nowadays many of them are still used as dwellings. Though built individually, these buildings are connected to adjacent buildings, forming blocks composed of aggregates. In order to analyze the seismic behavior of isolated buildings and aggregates, two typical central buildings and one typical corner building have been chosen. The two central buildings and the corner building are referred as C1, C2, and E buildings. Two corner buildings and two central buildings have been connected in order to simulate a block side. This aggregate is referred as AGG and it is composed by the following sequence of individual buildings: E-C1-C2-E. Original plans and drawings of existing buildings are then used to model these buildings. The modeled buildings have five stories. Standard pushover analyses lead to evaluate their seismic performance by means of capacity spectra and fragility curves. The analysis has been carried out in the parallel ( $U x$ ) and transversal (Uy) directions to the street. Then, a capacity spectrum based method is used to analyze the seismic behavior of these buildings considered as individual buildings and as an aggregate. Two earthquake scenarios are considered. The first one is a deterministic scenario which is based on a historical earthquake occurred in 1824, $25 \mathrm{~km}$ away from the city and the second one is a probabilistic scenario, which represents the ground motion with a probability of occurrence of $10 \%$ in 50 years. The soil local effects have been also considered and both scenarios have been used to assess the expected damage. Four non-null damage states are considered: slight (1), moderate (2), severe (3) and extensive-to-collapse (4). For the type of soil where most of the buildings are, and in the Ux direction, the four buildings show a similar behavior. The mean damage grade is 2.3 for the deterministic scenario and 2.7 for the probabilistic one. This means that moderate to severe damage is expected in both cases; furthermore, in the case of the deterministic scenario more than 10\% of the buildings would suffer extensive-to-collapse damage and nearly $20 \%$ for the probabilistic scenario, confirming the high vulnerability of such buildings. The differences in the expected damage are due to the significant different characteristics of the response spectra of the earthquake scenarios in the range of the fundamental periods of the buildings.
\end{abstract}

Keywords: unreinforced masonry buildings, aggregates, seismic performance, capacity spectra, fragility curves, seismic risk.

\section{Introduction}

During the twentieth century, world population has increased dramatically. Starting from the 1.6 billions in 1900 the world population currently is more than 6.6 billion people. The acceleration of the population pressure on our planet began in the nineteenth century and involves the massive occupation of land resulting in urban societies where people are organized in great cities. Modern cities, in addition to a very high population density, accumulate large numbers of buildings, infrastructures and facilities that result in a large concentration of socioeconomic value. One important cause of disasters is the poor seismic performance of buildings. The design and earthquake-resistant construction and seismic codes are excellent tools for improving the seismic behavior of structures, but many of the current buildings were built in the past without any consideration to seismic actions. This fact decisively increases the overall vulnerability and the seismic risk in these 
urban areas. Furthermore, the seismic behavior of engineered buildings, that have been designed and constructed according to codes, strongly depends on the technical level of the codes, which, in many cases, was not adequate. Some examples of how these factors may have contributed to the catastrophic damage that occurred in the past 15 years in the world, are the earthquakes occurred in Northridge (USA, 1994), Kobe (Japan 1995), Kocaeli (Turkey 1999), Nantou (Taiwan 1999), Kachch-Bhuj (India 2001), Niigata (Japan 2007), Wenchuan (China 2008), Haiti Region (Haiti 2010) and Offshore Maule (Chile 2010). Therefore, many buildings in urban areas have different levels of seismic vulnerability and some of them show an inadequate behavior during earthquakes. For this reason, many recent studies in earthquake engineering are oriented to the development, validation and application of techniques to improve the seismic capacity of buildings, e.g. to reduce their vulnerability, enabling better decision making on seismic risk prevention and protection. Improving the capacity requires the evaluation of seismic vulnerability and seismic physical damage. There are several methods for evaluation as well as numerous applications in urban areas (Whitman 1973; ATC-13 1985; Yepez et al. 1996; Barbat et al. 1998, 2006a, 2006b, 2008 and 2009; Lagomarsino and Giovinazzi 2006; Dolce et al. 2006; Carreño et al. 2007; Park et al. 2009 and Lantada et al. 2009 and 2010). The fragility and vulnerability of existing buildings can be evaluated from capacity curves, which are force-displacement diagrams that generally correspond to the maximum response of the structures corresponding to the fundamental mode of vibration. Capacity curves are derived from non-linear structural analysis and, in their acceleration displacement (AD) format, are called capacity spectra. From the capacity spectra, simplified techniques can be used to produce fragility curves. For each damage state, fragility curves determine its probability of exceedance in terms, for instance, of spectral displacement. The earthquake scenario is defined by means of $5 \%$ damped response spectra. Thus, advanced methods for estimating the seismic vulnerability and risk (FEMA/NIBS 2002; Milutinovic and Trendafiloski 2003) allow estimating the physical damage expected for an earthquake scenario by crossing the capacity spectrum, which defines the building, with the response spectrum, which defines the scenario. This procedure allows obtaining the performance point, which defines

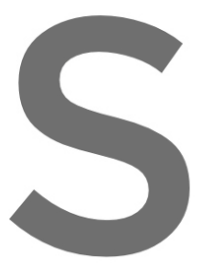
the spectral displacement produce in the building by the eartheuake corresponding to the selected scenario. Entering this spectral d obtained.

Barcelona is a city located in the western Mediterraner be found in Solé (197. (Permanyer 1990; Grau and Nada1 1997; Ribas 2004).

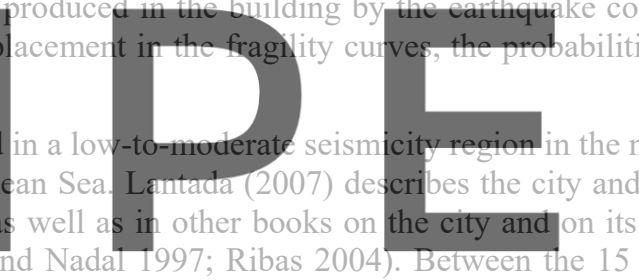

nized by the romans receiving the name of "Cologne Iulia Augusta Faventia Paterna Barcino". The current

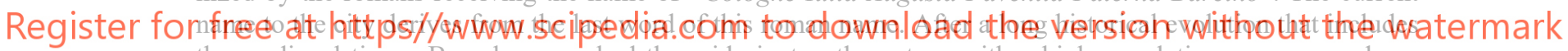
the medieval times, Barcelona reached the mid-nineteenth century with a high population pressure and oppressed by the medieval walls. It is in this context that generates the major urban expansion project, demolishing the walls and occupying the territory that separates the city from various villages in a vast area of land between the sea and the Collserola hills. During this era of expansion, which extends from the late nineteenth century until late in the twentieth century, most of the buildings constructed were unreinforced masonry buildings, forming aggregates that constitute typical building blocks, so called "manzanas" in Spanish. It is worth noting that today many of these buildings are more than one hundred years old. The main objective of this paper is to assess the vulnerability and seismic risk of these buildings considered as individual buildings and as aggregates. Aggregates are simulated by grouping individual buildings according to typical rows in front of a typical block. The methodology proposed by the Risk-UE project is used. In this method, the building is characterized by its bilinear capacity spectrum and the earthquake is defined by the $5 \%$ damped response spectrum. The structural analysis is performed by using the TREMURI computer program (Lagomarsino et al. 2008) that has been specifically developed for the analysis of unreinforced masonry buildings. The results show the high seismic vulnerability of this type of buildings confirming that a relatively small earthquake in Barcelona would cause significant damage.

\section{The Eixample}

Eixample means enlargement and it is the name of one of the ten districts of the city. In 1850, Barcelona city was still a walled city; in 1854 was promulgated the decree for the demolition of the walls. Thus, a vast space was opened from Barcelona to the small surrounding towns, which included the future districts of Horta, Gracia, San Andres, San Marti, Sarriá and Sants. Then, Barcelona could grow quickly. The planning of this area was subjected to a competitive public tendering. Not without controversy among architects and civil 
engineers and not without political reluctances, finally, the Plan of Cerdá of 1859 was enforced and, on September 4, 1860, Queen Elizabeth II laid the first stone of the first house of the Eixample, right in the Plaza de Catalonia. Fig. 1 shows an area of the Eixample district, near the Old City (Ciutat vella) district, as it was conceived and in its current state.

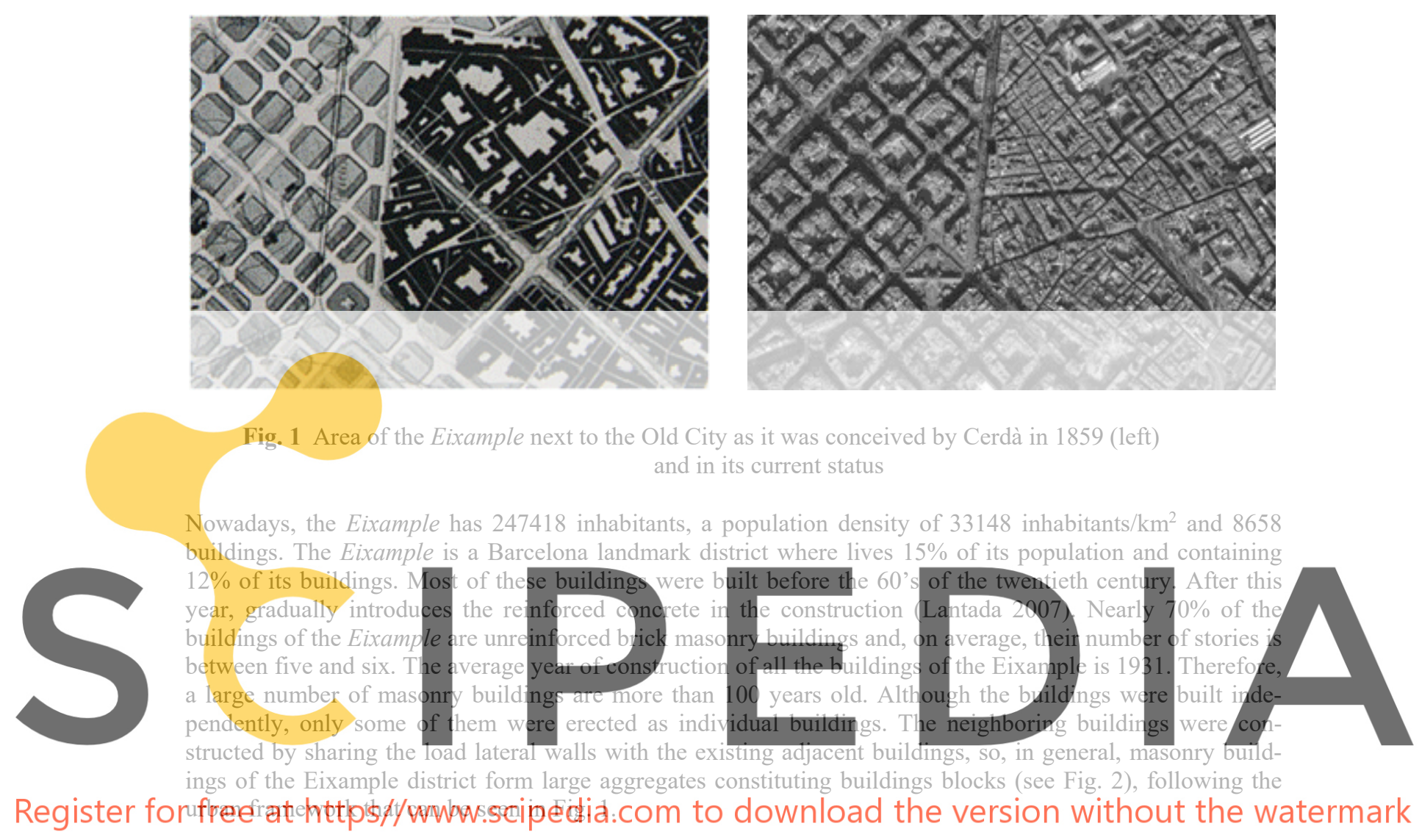

\section{Masonry buildlings of Barcelona}

Paricio (2001) describes the specific architectonic features of the masonry buildings of the Eixample district and Mari et al. (2003) describe some other technical aspects of this type of constructions. These buildings show very repetitive patterns and they are structures with load-bearing walls. Foundations are shallow running through surface pads under the walls or, in case of younger buildings, they are isolated foots under concrete pillars. The resistant elements are bearing walls, although in the ground floor there may also exist masonry pillars or cast iron pillars. Nevertheless, in general, these buildings only have the elements necessary to ensure the stability of the building. The walls of the street facade, of the interior courtyard of the block and the walls between buildings are the main bearing walls. In the first two stories, often there are metallic pillars and girders. This constructive solution for the first two floors are very common because it allows large open space permitting the ground floors being used for trading or catering activities in the ground floor and office or administrative activities in the mezzanines. However, it is worth noting that this option provides the systematic presence of soft ground floors in most of the buildings in the city. The walls of the main façade and of the courtyard façade are usually about $30 \mathrm{~cm}$ thick, but they have significant openings with windows and balconies. The walls between adjacent buildings are solid and they typically have a thickness of $15 \mathrm{~cm}$. In general, within a typical city block, there are two types of buildings: central buildings and corner buildings. Fig. 2 shows a drawing of the façade of a typical building. 

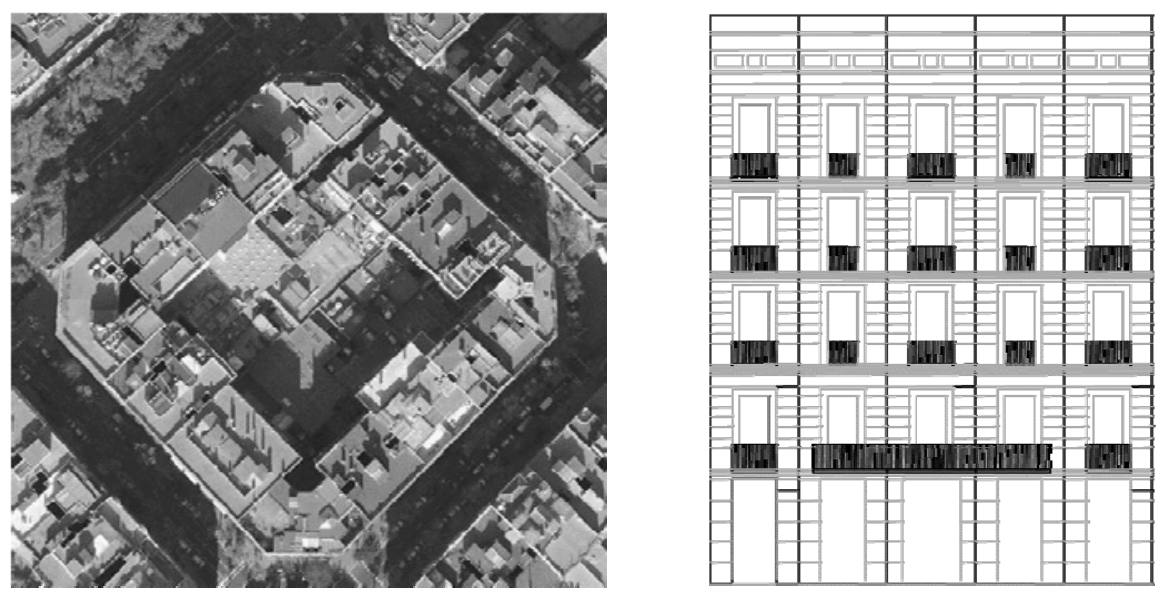

Fig. 2 Aerial view of a typical building block of the Eixample district (source: Google Earth) and sketch of a typical façade of a building

Central buildings are usually rectangular with a ratio between the main dimensions of 2 to 1 or higher. Corner buildings are more irregular, with a quasi-triangular shape due to the closure of the block corner. In addition, each building may contain one or more cores around the staircases and small internal courtyards made to provide natural light to the internal rooms. These cores are partially closed by masonry walls, which are 10, 15 or $20 \mathrm{~cm}$ thick; the floors are usually carried out in the transverse between the walls of the inner core and the walls between buildings by distributing the load on supports are built directly there is no internal courty internal courtyards betwe window gaps where inci levels, ranges from 20 d possible to find $10 \mathrm{~cm}$ thic into walls betwenn buildings
ard the se walls span the enti
adjacent building, these
(staircases) to $60 \mathrm{~cm}$ (façade n these walls. In th
gs. These walls us
wtire height and w
walls are irregula
thickness of load b
le wail). At the hig

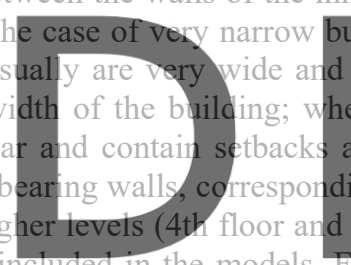
these buildings also have a secondary system of interior walls with different dimensions and importance. In

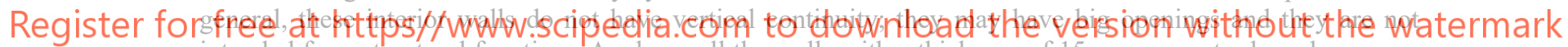
intended for a structural function. Anyhow, all the walls with a thickness of $15 \mathrm{~cm}$ or greater have been considered in the analysis. Only walls $5 \mathrm{~cm}$ thick have not been considered. In fact, the ratio between the areas of not inciuded and included walis is not significant and, in any case, it is lower than $10 \%$. The corner building geometry is more complex due to the irregular shape of the plant; in any case, the main inner and the external walls, corresponding to the façades and to the adjacent buildings, act as bearing walls. The distribution of the inner cores also is more irregular and complex. In general, corner buildings have a second internal bearing wall, which is parallel to the facade along its entire perimeter and there are walls of one or more internal cores, containing staircases or elevators or simply intended to provide light to the inner rooms. This way, corner buildings have bearing walls according to, at least, three directions: parallel to the two sides of the block and parallel to the main facade, which forms an angle of $45^{\circ}$ with the directions of the streets (see Fig. 2). In general, the inner walls, that can reach lengths of up to $10 \mathrm{~m}$, have been built without foundations and are poorly connected or not connected to the façades nor to the walls between adjacent buildings and, therefore, they cannot act as bracing walls. Furthermore, when there are openings for doors, windows or balconies, they give rise to lintels or parapets of variable dimensions; the wall sections over lintels or parapets are extremely weak areas where cracks, due to the effect of differential movements, can be observed.

\section{Model buildings}

Based on available architectonic drawings and structural plans of actual buildings (Paricio 2001), two central rectangular buildings and a typical corner building have been modeled. The rectangular buildings are referred as $\mathrm{C} 1$ and $\mathrm{C} 2$ and the corner building as E. Building $\mathrm{C} 1$ is more regular than building $\mathrm{C} 2$ (see Fig. 3 and Fig. 4). In order to analyze the differences between the behavior of individual buildings and aggregates four of these buildings are joined according to the sequence E-C1-C2-E. This aggregate simulates one side of a typi- 
cal block and it is referred AGG. This way the seismic behavior of isolated buildings as well as aggregates will be analyzed. Fig. 3 shows the three isolated buildings and the aggregate. Fig. 4 shows the plants of individual buildings; the internal hubs of the inner cores for courtyards, stairwells or elevators can be seen clearly. $\mathrm{C} 1$ model is based on architectural drawings of a building constructed in 1898. It has a facade of $17.55 \mathrm{~m}$, a length of $23.65 \mathrm{~m}$, a height of $17 \mathrm{~m}$ and it has five stories: ground floor, mezzanine and three upper stories. The heights of the first floor, the mezzanine and the rest of the stories are 4.5, 3.5 and $3 \mathrm{~m}$ respectively. The wall of the main façade has a thickness of $45 \mathrm{~cm}$ in the first two floors and $30 \mathrm{~cm}$ in the other floors. The internal façade is $30 \mathrm{~cm}$ thick. The thickness of the lateral walls is $30 \mathrm{~cm}$ on the ground floor and $15 \mathrm{~cm}$ in the rest of the floors. These lateral walls also have masonry columns, with a $30 \times 30 \mathrm{~cm}$ section, which go from the ground to the roof; the other interior walls are $15 \mathrm{~cm}$ thick. The building has a courtyard and two rectangular entrants that become inner courtyards when it is attached to similar adjacent buildings.
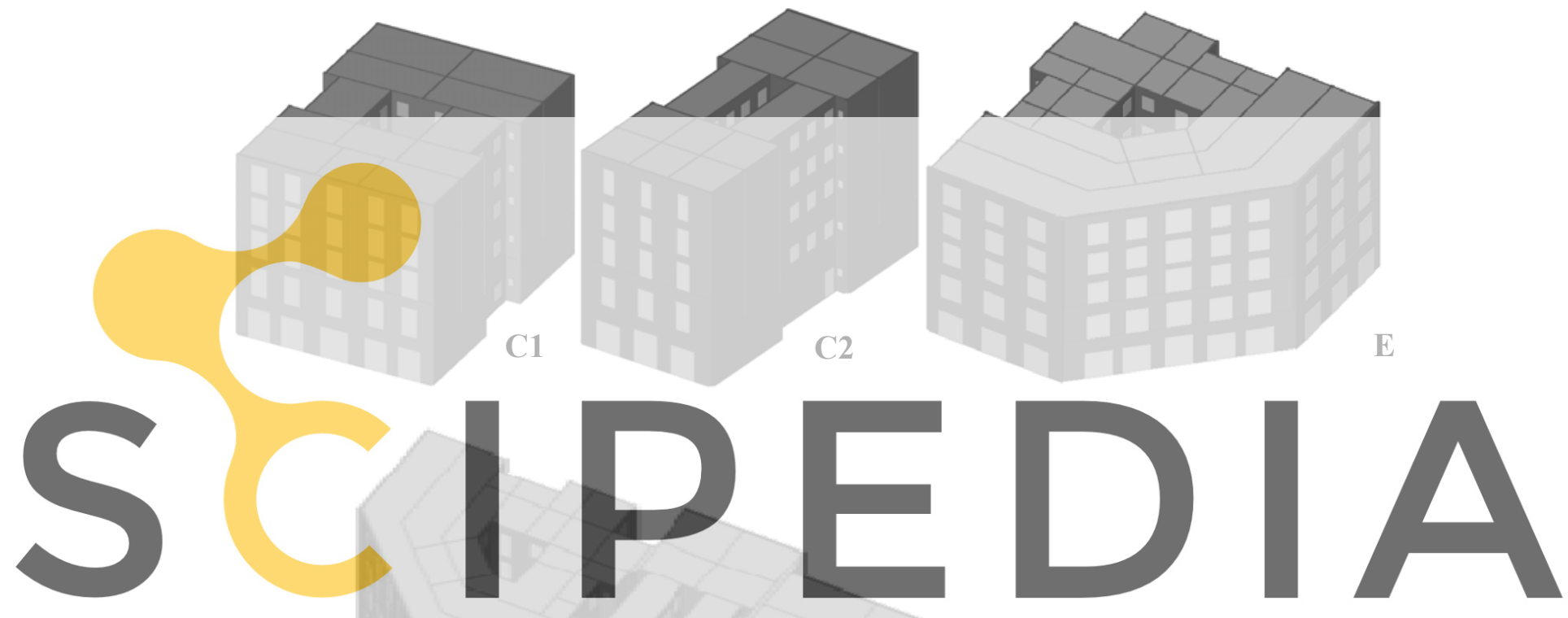

Register for free at https//www.scipedia.com to download the version without the watermark AGG

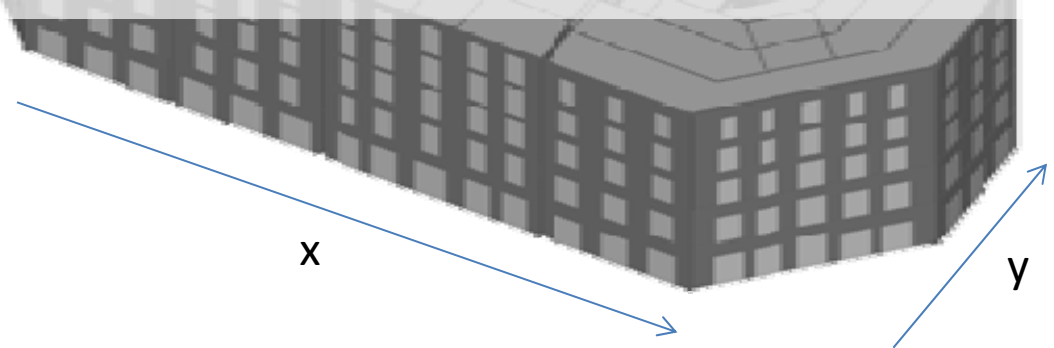

Fig. 3 Schemes of the buildings modeled. Individual buildings $\mathrm{C} 1, \mathrm{C} 2$ and $\mathrm{E}$ are shown above. Below the aggregate AGG is shown. This aggregate simulates one side of a typical block of the Eixample district and it is composed of individual buildings according to the sequence E-C2-C1-E, from left to right

C2 model is based on a building built in 1890 and the plant dimensions are $11.5 \times 26.57 \mathrm{~m}$. In height this building keeps the structure and dimensions of the building $\mathrm{C} 1$. The wall of the main facade has a thickness of $45 \mathrm{~cm}$ in the first two floors and $30 \mathrm{~cm}$ in the remaining three floors. The interior facade is $30 \mathrm{~cm}$ thick. There are other inner bearing walls $15 \mathrm{~cm}$ thick. The sidewalls have a thickness of $30 \mathrm{~cm}$ in the ground floor and 15 $\mathrm{cm}$ in the rest of the floors. These walls include brick columns with a section of $30 \times 30 \mathrm{~cm}$ going from the ground to the roof; this building, like the building $\mathrm{C} 1$, has an interior patio and two external rectangular entrants. E model is based on a corner building constructed in 1905. It is irregular and, in order to achieve a 
greater structural strength, it has up to three lines of interior walls parallel to the external façade of the building. The lack of connection between them and the lack of walls parallel to the lateral walls indicate that these buildings will have a poor behavior when subjected to horizontal loads. In height, the model has the same structure and dimensions as the previous two buildings; the plant size is $24.80 \times 24.65 \mathrm{~m}$ and the length of the chamfer is $20 \mathrm{~m}$; in the plan of Cerdá, these chamfers on the corners of the blocks were designed to improve the visibility of traffic at the crossings. The wall of the outer facade has a thickness of $60 \mathrm{~cm}$ on the ground floor, 45 on the mezzanine and 30 in the remaining floors, the inner facade is $30 \mathrm{~cm}$ thick and the interior walls are bearing walls of $15 \mathrm{~cm}$, except the walls of the stairwell on the first floor that are $20 \mathrm{~cm}$ thick.
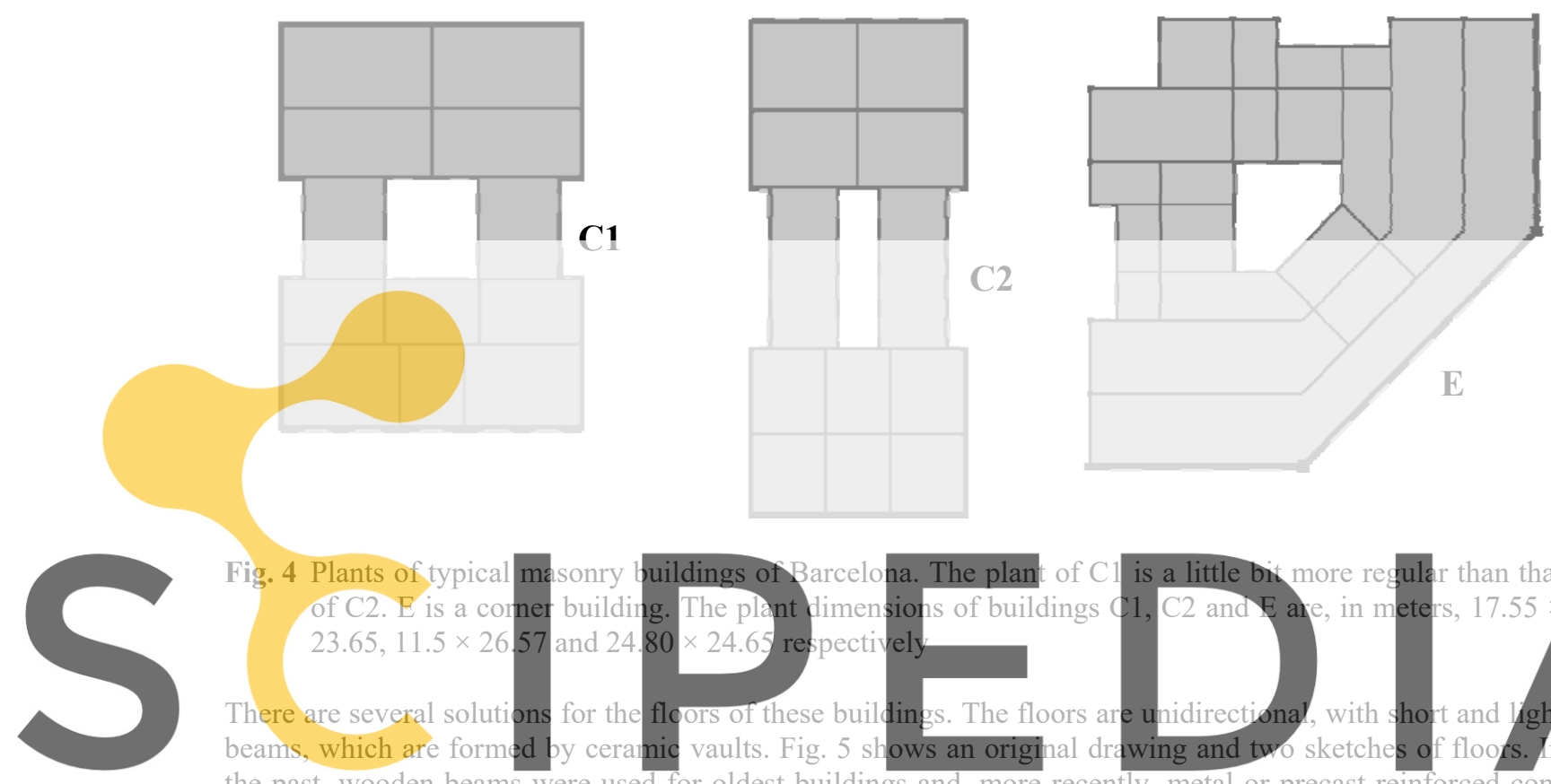

\section{the past, wooden beams were used for oldest buildings a}

crete beams were adopted as constructive solutions. Usually, floors do not have perimetrical bracings. In the

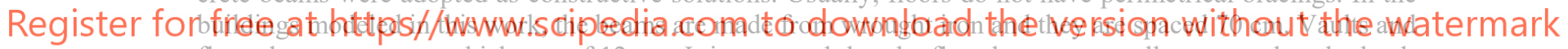

floors have an average thickness of $12 \mathrm{~cm}$. It is assumed that the floor beams are well connected to the load-

bearing masonry walls. Actually, the beams are simply leaning on bearing walls or girders. The original project structural plans, as well as several photos taken during restoration work (Paricio 2001), show details of beams leaning on perimetrical walls. In many cases the section leaning on the wall, is similar to but no greater than the beam section. Sometimes, it is also possible to see beams that cross the wall and go to about $50 \mathrm{~cm}$ beyond the wall limit. In both situations there are not anchoring elements. In some cases, it is possible to see simple supports in the zones where beams lean on walls. In all the cases, the beam-wall connection is good but this cannot be strictly considered as a rigid connection.

\section{Method}

The risk analysis is performed by using the method based on the capacity spectrum (Barbat et al. 2008). The earthquake is defined by the $5 \%$ damped response spectrum in its acceleration displacement (ADRS) format and earthquake scenarios are chosen according to the seismic hazard of the site. The buildings are described by their bilinear capacity spectra, which are defined by their yielding point (Dy, Ay) and by their ultimate capacity $(\mathrm{Du}, \mathrm{Au})$. To take into account the inelastic behavior of the structures, the elastic response spectrum is reduced to obtain the inelastic response spectrum, which is called the demand spectrum. Crossing demand and capacity spectra allows obtaining the performance point, which defines the spectral displacement that the earthquake scenario considered, would produce in the building. Among the different methods of obtaining this point (ATC-40 1996, Milutinovic and Trendafiloski 2003) the method of the equivalent linear displacement is used. The expected damage is then obtained from fragility curves. The method considers four nonnull damage states: 1 slight, 2 moderate, 3 severe and 4 extensive-to-complete. The meaning of these damage states or damage grades is well described in Grünthal (1998) and in Barbat et al. (2008). 

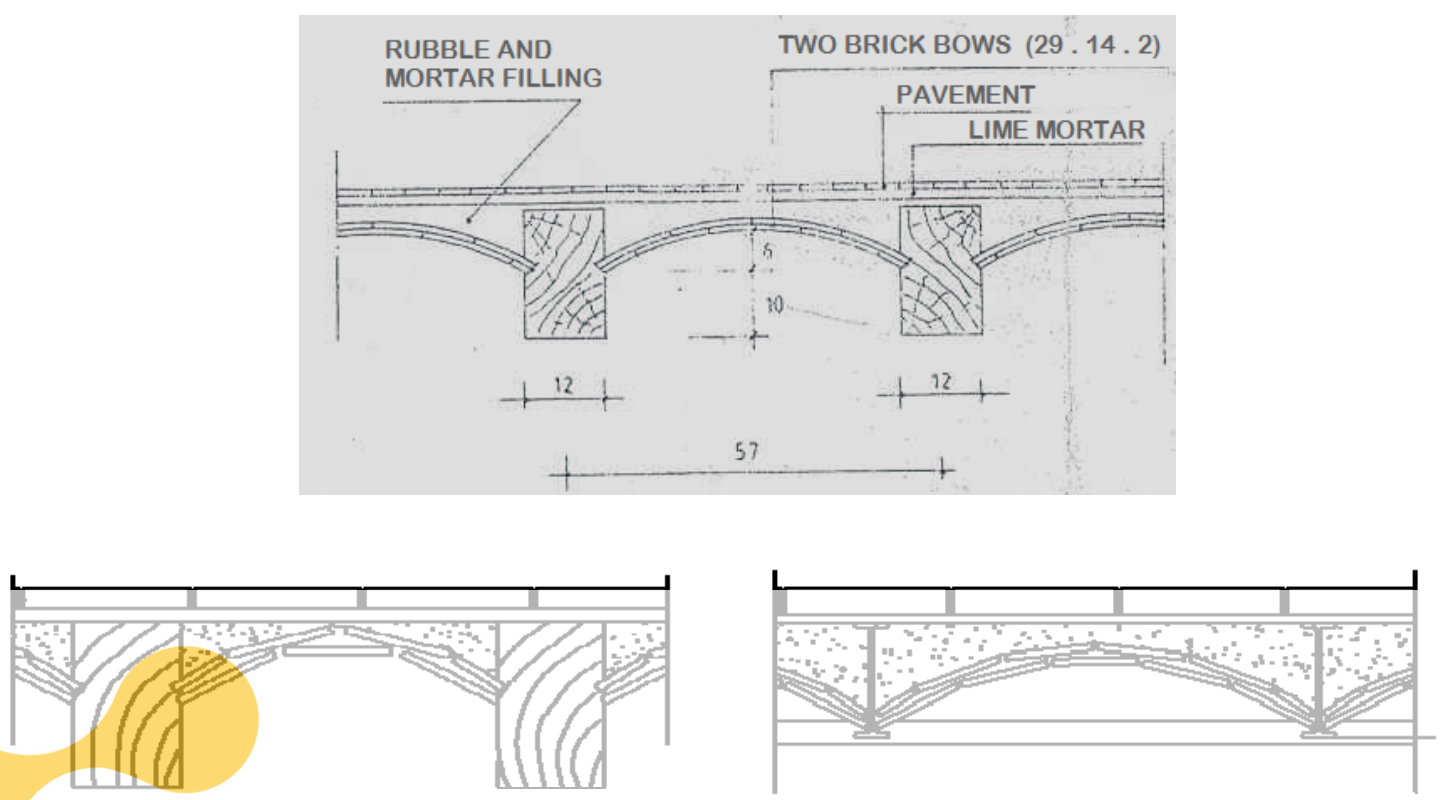

Fig. 5 Illustrations of typical floors. Old original drawing (above) and plots based on original sketches of

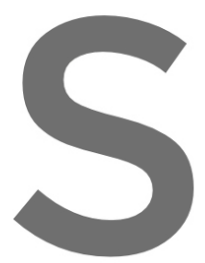
wood beams (left)

For each damage state,

ed. For the no-damage

assumed that fragility

(FEMA/NIBS 2002)
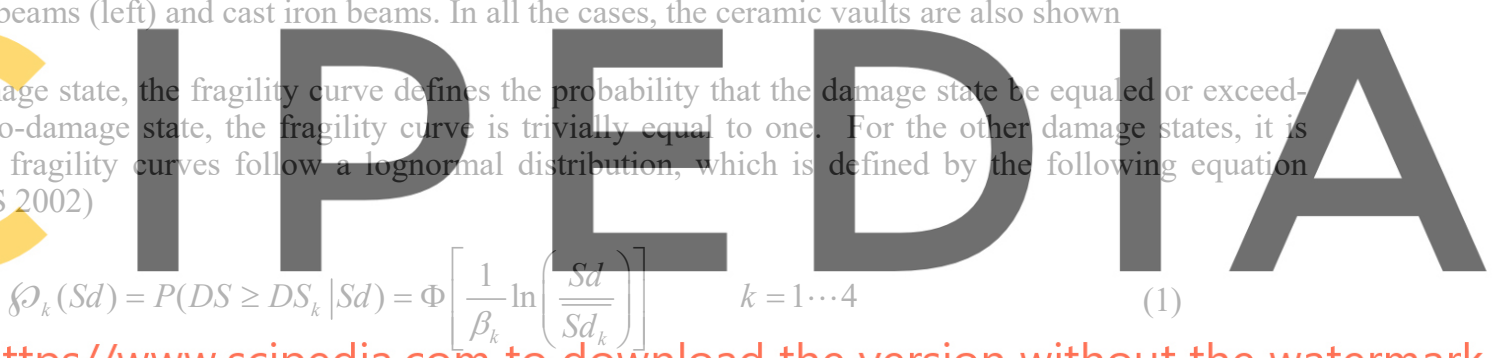

Register for free at https//www.scipedia.com to download the version without the watermark where $\Phi$ is the cumulative standard lognormal distribution function, $S d$ is the spectral displacement and $S d_{k}$ and $\beta_{k}$ are, respectively, the mean value and the standard deviation of the distribution function. Both parameters can be estimated from the bilinear capacity spectrum. The mean $\underline{S d} \underline{d}_{k}$ values, aiso calied damage thresholds, are determined by using the following conditions: $\overline{S d_{1}}=0.7 D y, \overline{S d}_{2}=D y,{\overline{S d_{3}}}=D y+0.25(D u-D y)$, and $\mathrm{Sd}_{4}=\mathrm{Du}$. To evaluate the standard deviations it is assumed that damage is distributed according to a binomial distribution (Grünthal 1998). Given that for the mean values, the probability of exceedance of the corresponding damage state is $50 \%$, assuming the binomial distribution allows calculating the probabilities of exceedance of the other damage states so that $\beta_{k}$ can be obtained from a least squares fit of the fragility curves to the computed exceedance probabilities, thus being completely defined the fragility curves. A more detailed description on how the values of $\beta_{k}$ are obtained can be found in Lantada et al. (2009). Therefore, for each building and for each earthquake scenario, the spectral displacement of the corresponding performance point can be input into the corresponding fragility curve to obtain the exceedance probabilities of each damage state. The probabilities of occurrence of each damage state $\left(P_{k}, k=0,1,2,3\right.$ and 4) are easily calculated from the exceedance probabilities and the mean damage grade $D_{m}$ can then be calculated by using the following equation:

$$
D_{m}=\sum_{k=0}^{4} k P_{k}
$$

Then, the parameter $d=D_{m} / 4$ is the parameter that defines the binomial damage distribution. This parameter allows recovering the probabilities of occurrence of each state of damage. These two parameters $d$ and $D_{m}$ are used below to discuss the results. 


\section{Capacity and fragility}

This section is devoted to the structural analysis of the individual buildings and of the aggregate in order to find the capacity spectra and fragility curves. To do that, and after a previous modal study of the structures, capacity curves are obtained by means of a pushover analysis. These curves are a representation of the shear at the base of the building as a function of the displacement at the roof. Then, the procedures and guidelines described in ATC-40 (1996) are followed in order to transform the capacity curve into the capacity spectrum in its bilinear form. The simplified method proposed in Risk-UE (Milutinovic and Trendafiloski 2003) has been used to obtain the corresponding fragility curves.

\subsection{TREMURI program}

3MURI is a computer program developed at the University of Genoa (Lagomarsino et al. 2008) allowing three-dimensional non-linear static analysis of masonry structures combined with elements of other materials such as, for instance, wood, iron or reinforced concrete, that are part of walls, beams or columns. The program evaluates the major in-plane failure modes of the masonry panels. Nevertheless, out-of-plane responses and the behavior to local bending of the floors are not taken into account by this software. This software is based on macro-elements. Based on mechanical hypotheses, each non-linear macro-element model may characterize a whole masonry panel allowing taking into account the two main in-plane masonry failure modes, bending-rocking and shear-sliding, including friction mechanisms. This way, this simplified model takes into account the evolution of damage by controlling the deterioration of the strength and degradation of the stiffness (Penna 2002; Galasco et al. 2006; Lagomarsino and Cattari 2009). Consequently, this program can be used for the design of new structures as well as for modeling and analyzing the seismic vulnerability of existing buildings. The dimensions of the macroelements depend on the geometry and dimensions of the considered storey, as well as on the dimensions of the openings and on the distances between them. For instance, a

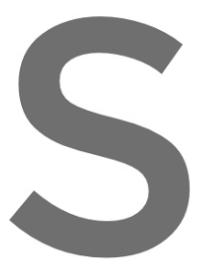
load-bearing wall can be well represented by one $n$ may need between thre as with the number of openin usually by means of 8 scribed in Lagomarsino

\section{2}
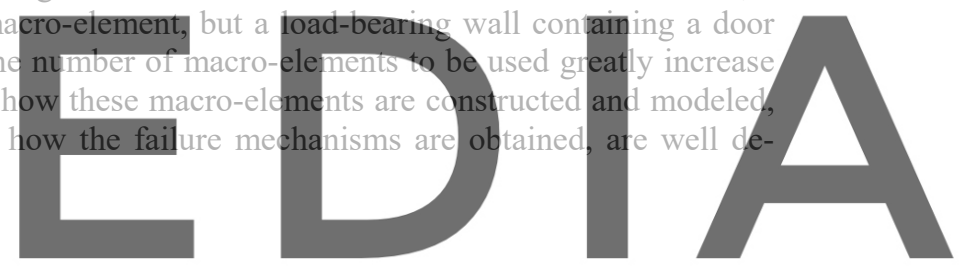

Moreno (2006) and Bonett (2003) describe the main characteristics and properties of the materials used in the

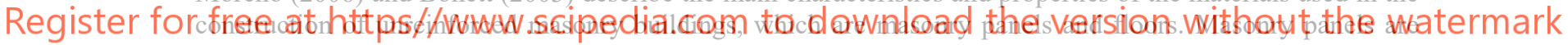
considered as made up of bricks and mortar. The same authors review the masonry strength to shear, to tension and to compression as well as its behavior under cyclic and dynamic loads; the in-plane and out-of-plane failure modes of the masonry panels are widely analyzed and discussed in these references. In fact, the TREMURI program uses macro-elements to model masonry buildings and incorporates the results of laboratory experiments, data coming from the analysis of real structures and other observations on the behavior of this type of buildings during earthquakes (Gambarotta and Lagomarsino 1997). The mechanical properties used in this study have been adjusted based on technical reports of restoration of unreinforced buildings of Barcelona and on the guidelines and judgment of architects and civil engineers with expertise on these types of materials and constructions. The main properties of the masonry walls and pillars are: specific mass, $\rho=1800 \mathrm{~kg} / \mathrm{m}^{3}$, Young's or elastic modulus, $E_{\mathrm{m}}=1800 \mathrm{MPa}$, shear modulus, $\mathrm{G}=300 \mathrm{MPa}$, shear strength, $\tau_{\mathrm{k}}=$ $0.20 \mathrm{MPa}$, and strength to compression $\sigma_{\mathrm{k}}=1.8 \mathrm{MPa}$. The vertical load, including dead and live loads, is $\mathrm{q}=5$ $\mathrm{kN} / \mathrm{m}^{2}$. Moreover, concerning the floors, the Young's or elastic modulus in the main direction, E1=958 MPa, and the shear modulus, $\mathrm{G}=25040 \mathrm{MPa}$, have been taken for the corresponding macroelements. It is worth noting that these macroelements contain all the components shaping the floor, including beams, ceramic vaults and mortar (see Fig. 5).

\subsection{Modal analysis}

Table 1 shows the main modal properties of the first three modes of vibration including the mass of the building, the period, and the mass contribution factors in each of the vibration directions. For buildings $\mathrm{C} 1$ and $\mathrm{E}$ translation modes correspond to first and second modes while the third mode of vibration correspond to the rotational mode. For building C2 and aggregate AGG the first and third modes correspond to translation and the second mode is the rotational mode. Only the translation modes are considered here. 
BULLETIN OF EARTHQUAKE ENGINEERING, 10(1), 2012, 331-349

Table 1.-Modal properties of the buildings

\begin{tabular}{ccccccccccccccc}
\hline & & \multicolumn{4}{c}{ Mode 1 } & \multicolumn{1}{c}{ Mode 2 } & \multicolumn{4}{c}{ Mode 3 } \\
\cline { 3 - 14 } Building & Mass & $\mathrm{T}$ & $\mathrm{M}_{\mathrm{x}}$ & $\mathrm{M}_{\mathrm{y}}$ & $\mathrm{M}_{\mathrm{z}}$ & $\mathrm{T}$ & $\mathrm{M}_{\mathrm{x}}$ & $\mathrm{M}_{\mathrm{y}}$ & $\mathrm{M}_{\mathrm{z}}$ & $\mathrm{T}$ & $\mathrm{M}_{\mathrm{x}}$ & $\mathrm{M}_{\mathrm{y}}$ & $\mathrm{M}_{\mathrm{z}}$ \\
$(\mathrm{Kg})$ & $(\mathrm{s})$ & $(\%)$ & $(\%)$ & $(\%)$ & $(\mathrm{s})$ & $(\%)$ & $(\%)$ & $(\%)$ & $(\mathrm{s})$ & $(\%)$ & $(\%)$ & $(\%)$ \\
\hline C1 & $1.5 \mathrm{E}+06$ & $\mathbf{0 . 4 5}$ & $\mathbf{8 6 . 6}$ & 0.0 & 0.0 & 0.41 & 0.0 & $\mathbf{8 1 . 0}$ & 0.0 & 0.39 & 0.1 & 0.1 & 0.0 \\
C2 & $1.2 \mathrm{E}+06$ & 0.56 & $\mathbf{8 6 . 8}$ & 0.0 & 0.0 & 0.43 & 0.0 & 0.0 & 0.0 & 0.35 & 0.0 & $\mathbf{8 0 . 2}$ & 0.0 \\
E & $2.0 \mathrm{E}+06$ & 0.44 & 26.5 & $\mathbf{4 9 . 4}$ & 0.01 & 0.42 & $\mathbf{5 2 . 7}$ & 30.58 & 0.0 & 0.38 & 1.5 & 0.28 & 0.0 \\
AGG & $6.8 \mathrm{E}+06$ & 0.45 & $\mathbf{7 8 . 9}$ & 0.04 & 0.0 & 0.42 & 3.8 & 8.9 & 0.0 & 0.40 & 0.2 & $\mathbf{7 1 . 2}$ & 0.0 \\
\hline
\end{tabular}

\subsection{Pushover analysis}

A pushover analysis, performed using the TREMURI program, allowed obtaining the capacity curves. The pattern of pushing forces is consistent with the fundamental mode of vibration and the analysis has been carried out in positive and negative directions of the $\mathrm{x}$ and $\mathrm{y}$-axis, which correspond respectively to the longitudinal and transverse directions. As shown in Fig. 3 the $\mathrm{x}$ direction is parallel to the street. The same procedure was applied to the four buildings in the four directions defined by \pm Ux and \pm Uy. Fig. 6 shows two examples of capacity eurves for building $\mathrm{C} 1$ and aggregate $\mathrm{AGG}$ analyzed in the +Ux direction.
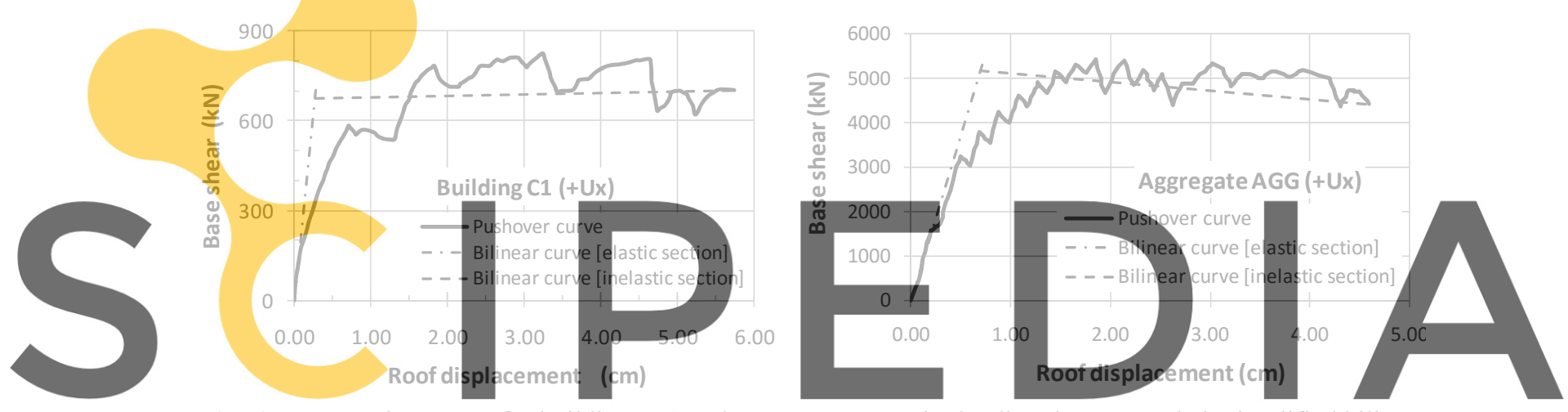

Fig. 6 Capacity curves for buildings $\mathrm{Cl}$ and aggregate $\mathrm{AGG}$, in the direction $+\mathrm{Ux}$. Their simplified bilin-

Register for free at htfps//WWW.Scipedia.com to download the version without the watermark

The procedure outlined in the ATC-40 (1996) has been used to transform the capacity curves into capacity spectra, which are given in its simplified bilinear form. Table 2 summarizes the parameters of the bilinear capacity spectra in the directions Ux and Uy. The analysis of fragility and expected damage will be also performed in these two directions.

Table 2

Parameters of the simplified bilinear capacity spectra

\begin{tabular}{ccccccccc}
\hline \multirow{3}{*}{ Building } & $\begin{array}{c}\text { Dy Direction } \\
(\mathrm{cm})\end{array}$ & $\begin{array}{c}\text { Ay } \\
(\mathrm{g})\end{array}$ & $\begin{array}{c}\text { Du } \\
(\mathrm{cm})\end{array}$ & $\begin{array}{c}\mathrm{Au} \\
(\mathrm{g})\end{array}$ & $\begin{array}{c}\text { Dy } \\
(\mathrm{cm})\end{array}$ & $\begin{array}{c}\text { Ay } \\
(\mathrm{g})\end{array}$ & $\begin{array}{c}\mathrm{Du} \\
(\mathrm{cm})\end{array}$ & $\begin{array}{c}\mathrm{Au} \\
(\mathrm{g})\end{array}$ \\
\hline $\mathrm{C} 1$ & 0.22 & 0.05 & 4.52 & 0.05 & 0.52 & 0.11 & 1.65 & 0.11 \\
$\mathrm{C} 2$ & 0.19 & 0.02 & 5.17 & 0.02 & 0.50 & 0.11 & 0.77 & 0.12 \\
E & 0.91 & 0.12 & 2.55 & 0.11 & 0.37 & 0.15 & 1.67 & 0.14 \\
AGG & 0.49 & 0.09 & 3.23 & 0.08 & 0.49 & 0.15 & 1.82 & 0.14 \\
\hline
\end{tabular}

\subsection{Fragility curves}

The method implemented in the Risk-UE project (Milutinovic and Trendafiloski 2003) as described above, in section 0 , has been used to assess the fragility curves of the buildings. Table 3 contains the parameters that define the fragility curves of the buildings when the seismic action is considered in the Ux direction. Table 4 has the parameters of the fragility curves in the direction Uy. Fig. 7 shows the fragility curves of the corner building, E, and of the aggregate AGG, when the analysis is performed in the direction Ux. 
Table 3

Mean values and standard deviations of the fragility curves of the four buildings considered in the direction Ux. Units of the spectral displacement are $\mathrm{cm}$.

\begin{tabular}{ccccccccc}
\hline \multirow{2}{*}{ Building } & \multicolumn{2}{c}{ Slight } & \multicolumn{4}{c}{ Damage states } \\
& \multicolumn{2}{c}{${ }^{2}$} & \multicolumn{2}{c}{ Moderate } & \multicolumn{2}{c}{ Severe } & \multicolumn{2}{c}{$\begin{array}{c}\text { Extensive-to- } \\
\text { collapse }\end{array}$} \\
\cline { 2 - 10 } & $\overline{S d_{1}}$ & $\beta_{1}$ & $\overline{S d_{2}}$ & $\beta_{2}$ & $\overline{S d_{3}}$ & $\beta_{3}$ & $\overline{S d_{4}}$ & $\beta_{4}$ \\
\hline C1 & 0.16 & 0.27 & 0.22 & 0.30 & 1.20 & 1.24 & 4.52 & 0.98 \\
C2 & 0.14 & 0.27 & 0.20 & 0.33 & 1.29 & 1.35 & 5.17 & 1.00 \\
E & 0.64 & 0.28 & 0.91 & 0.32 & 1.38 & 0.43 & 2.55 & 0.50 \\
AGG & 0.34 & 0.28 & 0.54 & 0.51 & 1.21 & 0.78 & 3.23 & 0.79 \\
\hline
\end{tabular}

Table 4

Mean values and standard deviations of the fragility curves of the four buildings considered in the direction Uy. Units of the spectral displacement are $\mathrm{cm}$.
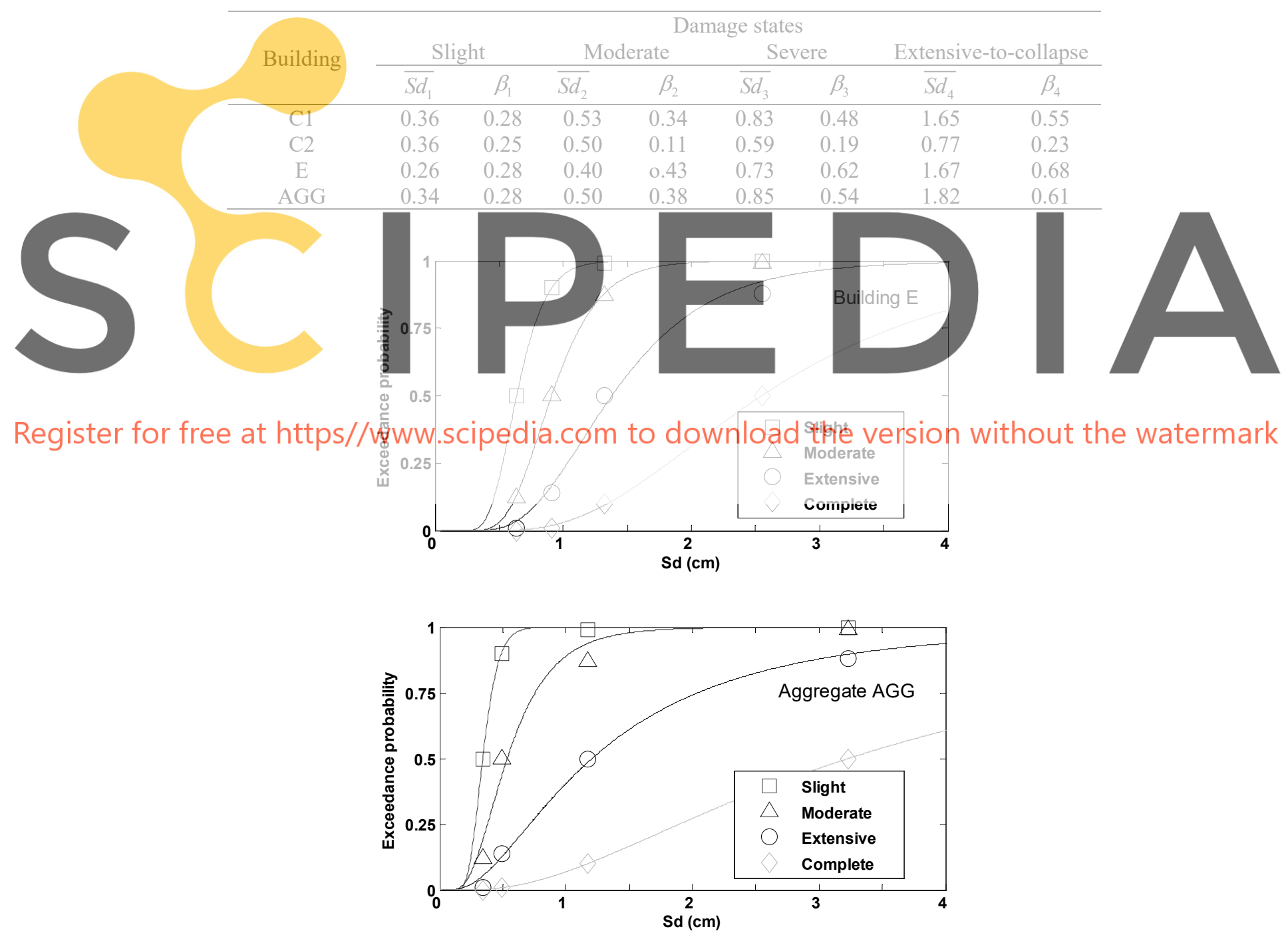

Fig. 7.- Fragility curves of the buildings $\mathrm{E}$ (above) and aggregate AGG, in the direction Ux 


\section{Earthquake scenarios}

The city of Barcelona is located in a low-to-moderate seismic hazard region. The macroseismic intensity with a return period of 475 years is between the grades VI and VII in the European macroseismic scale EMS'98. In the framework of the Risk UE project, Irizarry (2004) developed two scenarios, specific to the city of Barcelona, in terms of $5 \%$ damped elastic response spectra. The first scenario, which is called deterministic scenar$i o$, is based on a historical earthquake occurred $25 \mathrm{~km}$ away from Barcelona. The second scenario, which is called probabilistic scenario, matches the ground motion with a $10 \%$ probability of occurrence in 50 years, that is, the 475 return period ground motions. Local site effects were also considered. Seismic microzoning studies of the soils of Barcelona, as proposed by Cid (1998) and Cid et al. (2001) were used by Irizarry (2004) to obtain specific site response spectra for these two scenarios and for the four soil types identified in the city. Table 5 shows the S-wave velocities of the four soil types and the correspondence between soil types in the city and those considered in the Eurocode EC8 (2004).

Table 5

Soil types in Barcelona. The typical shear wave velocities and the equivalent soil types as defined by the Eurocode (EC8 2004) are assigned to each one of the four zones of the city.

\begin{tabular}{ccc}
\hline Zone & Vs $(\mathrm{m} / \mathrm{s})$ & Eurocode \\
\hline I & 225 & $\mathrm{C}$ \\
II & 384 & $\mathrm{~B}$ \\
III & 405 & $\mathrm{~B}$ \\
R & 800 & $\mathrm{~A}$ \\
\hline
\end{tabular}

Fig. 8 a) shows an outline of the city with its 10 districts. Fig. 8 b) shows the four seismic zones of the city. Zone R corresponds to good quality soils including rock outcrops, Zone I has very soft soils and it includes the areas near the waterfront as well as the deltas of the rivers Besós, northeast, and Llobregat, to the southwest. Zones II and III correspond to intermediate quality soils, respectively located near soil type I and soil type R. Fig. 8 c) shows the $5 \%$ damped elastic response spectra for the deterministic scenario and Fig. 8 d) shows the response spectra for the probabilistic scenario. Fig. 8 a) and Fig. 8 b) show how the Eixample district is almost entirely located on soil type II. It is in this zone where most of the unreinforced masonry buildings, aggregates, and typical blocks of the city, are located. Therefore, the results obtained for this soil type will be mainly used for the discussion of the results.

\section{Expected damage}

The method described in section 0 has been used to assess the damage expected, which is quantified by means of the mean damage grade $D_{m}$. Table 6 summarizes the mean damage grades obtained when the buildings are analyzed in the Ux direction. Fig. 9 shows the corresponding bar diagrams. Table 7 shows the expected damage when the analysis is carried out in the direction Uy. The damage obtained for the probabilistic scenario is greater than that obtained for the deterministic one. However, the increase of the damage is different for different buildings. For instance, in Table 6, which correspond to the analysis in the direction Ux, and for the soil type $\mathrm{R}$, the mean damage grade obtained for the corner building $\mathrm{E}$ is 0.5 for the deterministic scenario and 1.3 for the probabilistic scenario. But, in the cases of the buildings $\mathrm{C} 1$ and $\mathrm{C} 2$, the differences in the damage expected are much less; indeed, the mean damage grades respectively are 2.2 and 2.3 for the deterministic scenario and 2.3 and 2.4 for the probabilistic scenario. In the direction Uy, (see Table 7) the differences in the expected damage between the deterministic and probabilistic scenarios are more important. A similar effect is observed when comparing the behavior of the buildings in different types of soils; buildings are more damaged in soft soils (Zone I). Differences in the expected damage in the Ux and in the Uy directions (see Table 6 and Table 7) do not follow a systematic pattern of variation. Thus, for instance, for the deterministic scenario and hard soils (Zone R), buildings C1, C2 and aggregate AGG are more damaged in the direction Ux than in the direction $\mathrm{Uy}$, but building $\mathrm{E}$ is more damaged in the direction $\mathrm{Uy}$; the variation patterns of the expected damage in the other soil zones are different. For the probabilistic scenario, the expected damage in the direction $\mathrm{Uy}$ only is lesser for building $\mathrm{C} 1$ and aggregate AGG. 

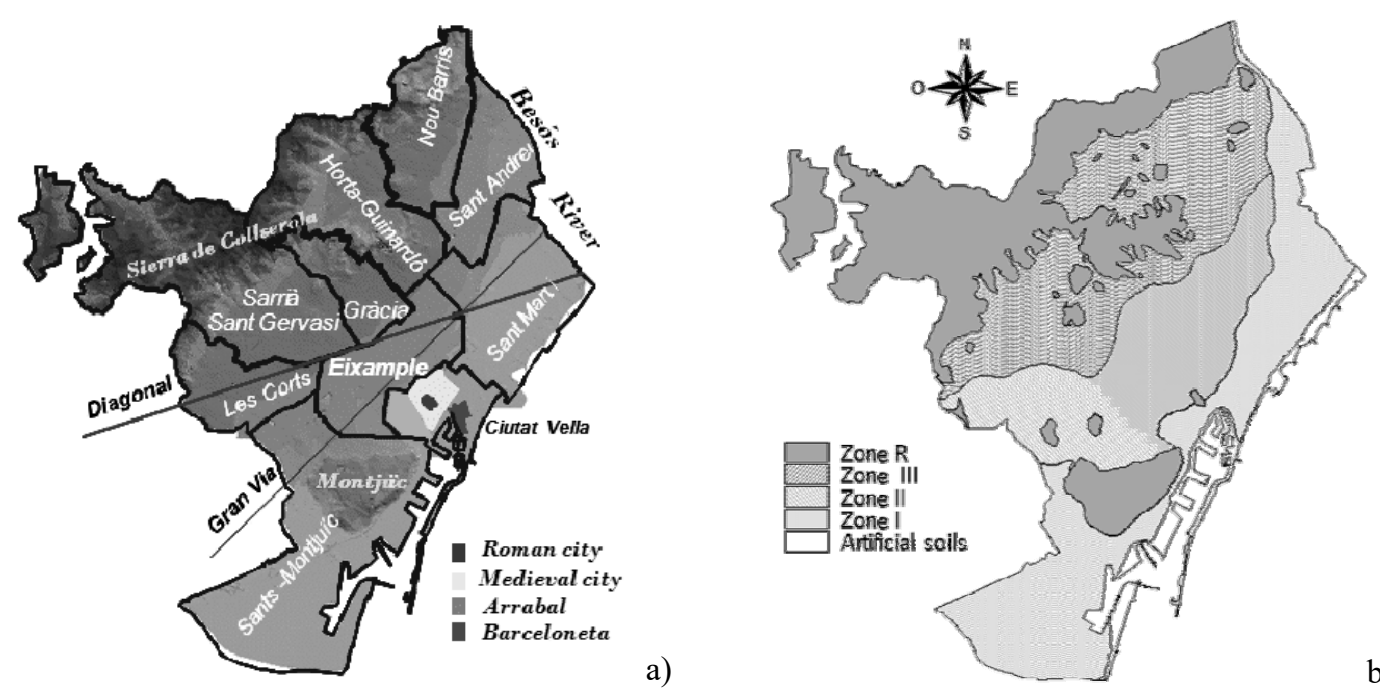

b)
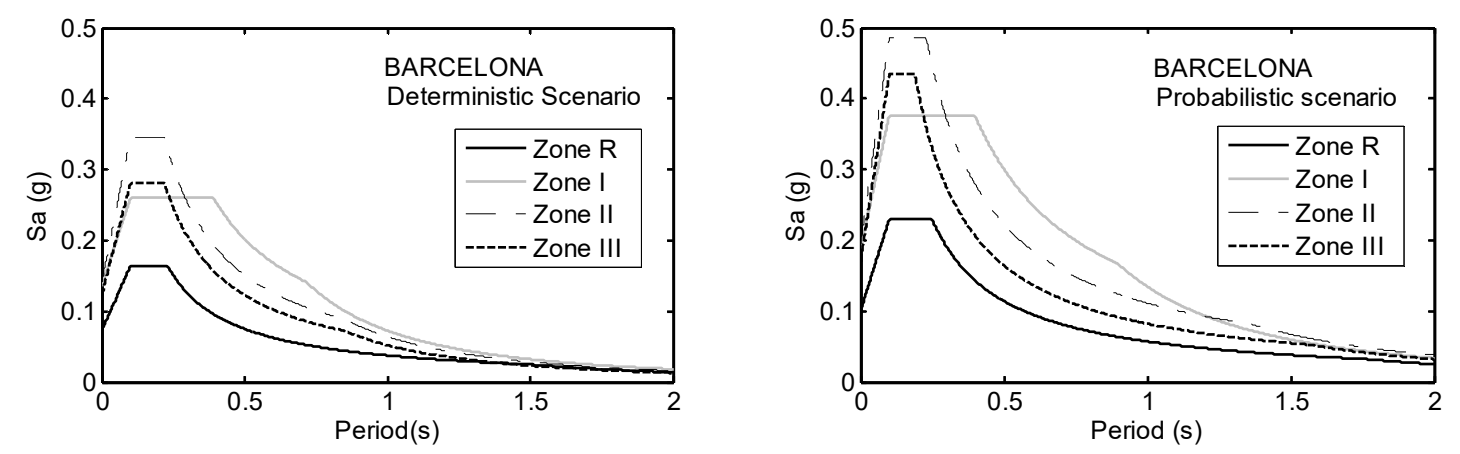

c)

Fig. 8 a) Sketch of the city of Barcelona with its ten districts. b) Seismic zoning of the city. Four main soil types are identified. c) $5 \%$ damped elastic response spectra for the deterministic scenario.

d) $5 \%$ damped elastic response spectra for the probabilistic scenario

For soil zones I, II and III, in general, the expected damage in the direction Uy is larger than in the direction Ux for buildings $\mathrm{C} 1$ and $\mathrm{C} 2$, but it is similar for the buildings $\mathrm{E}$ and AGG. Finally, and with only three exceptions, see zones I and II of the probabilistic scenario in Table 6, and zone R of the deterministic scenario in Table 7, the most damaged building is the building $\mathrm{C} 2$, probably because of its geometric characteristics.

\section{Discussion and conclusions}

The unreinforced masonry buildings analyzed in this work belong to the Eixample district and, since almost this entire emblematic district is located in the soil zone II, the average damage grade for this zone is used for discussion. Furthermore, concerning the buildings, although the analysis has been performed in the Ux and Uy directions, the discussion is focused on the Ux direction, because it is in this direction that the individual buildings are joined to compound the aggregate. Moreover, it is expected that the behavior of the aggregate in the Uy direction be similar to that of the individual buildings in the same direction. The average value of the mean damage grade corresponding to soil zone II in the deterministic and probabilistic scenarios of Table 6 are 2.30 and 2.67 respectively. These values indicate that the expected damage in unreinforced masonry buildings of Barcelona is between moderate and severe damage. The binomial probability distribution is then used to obtain the probabilities of each damage state. Table 8 shows damage probability matrices for these two mean damage values; so $D_{m}$ in this Table is the mean damage grade, and $d$ is the parameter controlling the binomial distribution which is computed according to equation (2); P(Dsk) are the probabilities of each damage state, and $\mathrm{k}=0,1,2,3,4$, identifies the corresponding damage state. The expected damage is high. 
Table 6

Mean damage grades, $D_{m}$, expected for the four buildings and for the two earthquake scenarios. Direction Ux.

\begin{tabular}{ccccccccc}
\hline & \multicolumn{3}{c}{ Deterministic scenario } & \multicolumn{4}{c}{ Probabilistic scenario } \\
\cline { 2 - 8 } Building & \multicolumn{3}{c}{ Soil type } & \multicolumn{4}{c}{ Soil type } \\
\cline { 2 - 8 } & R & I & II & III & R & I & II & III \\
\hline C1 & 2.2 & 2.5 & 2.4 & 2.3 & 2.3 & 2.7 & 2.6 & 2.4 \\
C2 & 2.3 & 2.7 & 2.5 & 2.4 & 2.4 & 2.9 & 2.7 & 2.6 \\
E & 0.5 & 2.6 & 2.1 & 1.5 & 1.3 & 3.2 & 2.8 & 2.2 \\
AGG & 1.3 & 2.5 & 2.2 & 2.0 & 1.9 & 2.9 & 2.6 & 2.3 \\
\hline
\end{tabular}

Table 7

Mean damage grades, $D_{m}$, expected for the four buildings and for the two earthquake scenarios. Direction Uy.

\begin{tabular}{ccccccccc}
\hline & \multicolumn{4}{c}{ Deterministic scenario } & \multicolumn{4}{c}{ Probabilistic scenario } \\
\cline { 2 - 8 } Building & \multicolumn{3}{c}{ Soil type } & \multicolumn{4}{c}{ Soil type } \\
\cline { 2 - 8 } & R & I & II & III & R & I & II & III \\
\hline C1 & 0.9 & 2.9 & 2.5 & 2.1 & 1.9 & 3.4 & 3.0 & 2.6 \\
C2 & 0.8 & 3.9 & 3.5 & 3.0 & 2.7 & 3.9 & 3.9 & 3.7 \\
E & 1.0 & 2.4 & 2.3 & 2.0 & 1.8 & 2.8 & 2.8 & 2.4 \\
AGG & 0.7 & 2.5 & 2.2 & 1.8 & 1.7 & 3.0 & 2.8 & 2.3 \\
\hline
\end{tabular}
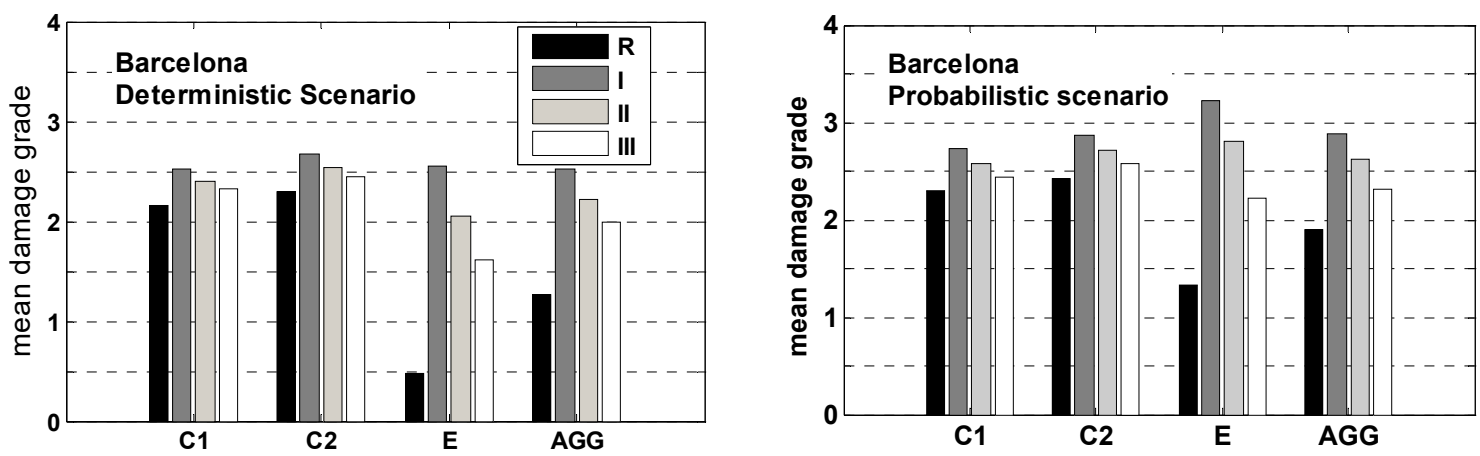

Fig. 9 Mean damage grades, $D_{m}$, for the deterministic (left) and probabilistic scenarios (see also Table 6)

Table 8

Mean damage grades, $D m$, parameter of the binomial probability distribution, $d$, and probabilities of the damage states (in \%) expected in the soil Zone II for the two earthquake scenarios considered. Direction Ux.

\begin{tabular}{cccccccc}
\hline \multirow{2}{*}{ Scenario } & \multirow{2}{*}{$D_{m}$} & \multirow{2}{*}{$d$} & \multicolumn{5}{c}{ Damage states probabilities (\%) } \\
\cline { 4 - 8 } & & $\mathrm{P}(\mathrm{Ds} 0)$ & $\mathrm{P}(\mathrm{Ds} 1)$ & $\mathrm{P}(\mathrm{Ds} 2)$ & $\mathrm{P}(\mathrm{Ds} 3)$ & $\mathrm{P}(\mathrm{Ds} 4)$ \\
\hline Deterministic & 2.30 & 0.5750 & 3.3 & 17.7 & 35.8 & 32.3 & 10.9 \\
Probabilistic & 2.67 & 0.6675 & 1.2 & 9.8 & 29.6 & 39.6 & 19.8 \\
\hline
\end{tabular}

For the deterministic scenario, more than $10 \%$ of buildings suffer damage grade 4 while for the probabilistic scenario, almost $20 \%$ of the buildings would suffer this damage state. In the damage state Ds 4 , they are included the buildings suffering extensive or generalized damage or collapse. Namely, it is usually considered that in this damage category are included all the buildings for which the estimated repair cost exceeds the $60 \%$ of the replacement cost. Furthermore, the number of buildings suffering this damage grade has a great impact on three key issues of seismic disasters such as homeless people, the volume of debris and the number of casualties including deaths and injured people. The analysis in the direction Uy for the same type of soil 
produces results comparable although slightly higher. In our view, the two most relevant results of this study are the following. 1) The old unreinforced masonry buildings of Barcelona are extremely vulnerable, in such a way that they may cause catastrophic effects in case of earthquake. 2) For soil type II and in the Ux direction, the aggregate does not improve significantly the seismic behavior of isolated buildings; rather the aggregate seems to inherit the shortcomings of seismic strength of the individual buildings from which it is compound. However as it can be seen in Table 6, for the two earthquake scenarios considered and for the four soil types, the expected damage in the aggregate is a sort of average of the damage expected for the individual buildings. It is worth noting that this average must include two corner buildings. Moreover, the interpretation of the results obtained in the direction Uy is different (see Table 7); in this direction of the analysis, the expected damage of the aggregate is similar to the lower value obtained for the individual buildings. This may be because in the AGG, buildings $\mathrm{C} 1, \mathrm{C} 2$ and $\mathrm{E}$ perform like isolate buildings having some confinement, which may produce a small improvement of their individual behavior. In any case, the expected damage depends on the geometry of the building as well as on the soil quality. In the direction Ux, aggregate AGG and building E show a better performance when they are founded on rock; while in lower quality soils, the expected damage is similar for all the buildings. The building $\mathrm{C} 1$ performs better than $\mathrm{C} 2$; soft soils increase the expected damage and the probabilistic scenario is slightly more damaging than the deterministic one. In the direction Ux and for all types of soils, the damage suffered by the buildings $\mathrm{C} 1$ and $\mathrm{C} 2$ is similar, while the building $\mathrm{E}$ and aggregate AGG show a better behavior on hard soils than in soft soils; the behavior of these two buildings is more sensitive to the soils quality than the buildings $\mathrm{C} 1$ and $\mathrm{C} 2$. All the buildings perform better on hard rock soils than in other soil types, but as it can be seen in Table 6 and Table 7, this effect is more relevant in the Uy direction. In both directions, $\mathrm{Ux}$ and $\mathrm{Uy}$, this effect relative to the soil quality is more notable for the deterministic scenario than for the probabilistic one. In the direction Ux and for the deterministic scenario, the building $\mathrm{C} 2$ shows a relatively poorer performance, which probably is due to the geometry of the plant in this direction. In this same direction Ux, the expected damage for the probabilistic scenario, although larger, is similar to that in the deterministic scenario. These significant differences in the damage expected for different directions and scenarios may be due to the combined effects of buildings strengths, of their eigen periods as well as to the differences on the amplification levels and frequency contents of the response spectra for different soils.

\section{Acknowledgements}

The thorough revision of the paper of two anonymous referees is greatly appreciated. The thoughtful comments and suggestions of the reviewers helped to improve the manuscript. This work has been partially sponsored by the Geological Institute of Catalonia (IGC), by the Science and Education Ministry of Spain, by the European Commission and with FEDER grants through the research projects CGL-2005-04541-C03-02/BTE, CGL2008-00869/BTE， HABITAT-2030-PSS-380000-2005-14, SEDUREC-CONSOLIDER-CSD200600060, INTERREG: POCTEFA 2007-2013/ 73/08 and MOVE- FT7-ENV-2007-1-211590.

\section{References}

ATC-13 (1985) Earthquake damage evaluation data for California, Applied Technology Council, Redwood City, California

ATC-40 (1996) Seismic evaluation and retrofit of concrete buildings. Technical report, Applied Technology Council, Redwood City, California

Barbat AH, Mena U, Yépez F (1998) Evaluación probabilista del riesgo sísmico en zonas urbanas, Revista internacional de métodos numéricos para cálculo y diseño en ingeniería, 14(2) 247-268

Barbat AH, Lagomarsino S, Pujades LG (2006a) Vulnerability assessment of dwelling buildings. In: Oliveira CS, Roca A, Goula X (ed) Assessing and Managing Earthquake Risk. Springer. Dordrecht, pp 115-134

Barbat AH, Pujades LG, Lantada N, R. Moreno R. (2006b) Performance of buildings under earthquake in Barcelona, Spain. Computer-Aided Civil and Infrastructure Engineering 21: 573-593

Barbat AH, Carreño ML, Pujades LG, Lantada N, Cardona OD and Marulanda MC (2009) Seismic vulnerability and risk evaluation methods for urban areas. A review with application to a pilot area. Structure and Infrastructure Engineering 6(1): 17-38 
Barbat AH, Pujades LG, Lantada N,. MorenoR (2008) Seismic damage evaluation in urban areas using the capacity spectrum method: application to Barcelona. Soil Dynamics and Earthquake Engineering 28 (10-11): 851-865

Bonett R (2003) vulnerabilidad y riesgo sísmico de edificios Aplicación a entornos urbanos en zonas de amenaza alta y moderada. Dissertation. Universidad Politécnica de Cataluña. Barcelona. Spain. http://www.tdx.cat/TDX-1222103-092523. Accessed 1 June 2010

Carreño ML, Cardona OD, Barbat AH (2007) Urban seismic risk evaluation: A holistic approach. Natural Hazards 40: 137-172

Cid J (1998) Zonificación sísmica de la ciudad de Barcelona basada en métodos de simulación numérica de efectos locales. Dissertation. Universidad Politécnica de Cataluña. Barcelona, Spain.

Cid J, Susagna T, Goula X, Chavarria L, Figueras S, Fleta J, Casas A, Roca A (2001) Seismic zonation of Barcelona based on numerical simulation of site effects. Pure Appl Geophys 158: 2559-2577

Dolce M, Kappos A, Masi A, Penelis G and M Vona M (2006) Vulnerability assessment and earthquake damage scenarios of the building stock of Potenza (Southern Italy) using Italian and Greek methodologies. Engineering Structures 28: 357-371

EC8 (2004) Design of structures for earthquake resistance - Part 1: General rules, seismic actions and rules for buildings, EN 1998-1:2004:E, December 2004

FEMA/NIBS (2002) HAZUS Technical Manual -SR2, Federal Emergency Management Agency, FEMA \& National Institute of Building Sciences, NIBS, Washington D.C., Vol. 1, 2, 3

Galasco A, Lagomarsino S, Penna A (2006) On the use of pushover analysis for existing masonry buildings. Proc. of the 13th European Conference on Earthquake Engineering, Geneva ( $\mathrm{CH})$, 3-8 September 2006, ID 1080

Gambarotta L, Lagomarsino S (1997) Damage model for the seismic response of brick masonry shear walls. Part II: the continuum model and its applications. Earthquake Engineering and Structural Dynamics 26: 441-462

Grau R, Nadal M (1997) La unificació municipal del pla de Barcelona 1874-1897. Institut municipal d'Història de Barcelona. Ed Proa. Barcelona. Spain

Grünthal G Ed (1998) European Macroseismic Scale 1998, vol. 15. Luxemburg: Centre Européen de Géodynamique et Séismologie, Cahiers du Centre Européen de Géodynamique et de Séismologie;1998

Irizarry J, Goula X, Susagna T (2003) Analytical formulation for the elastic acceleration-displacement response spectra adapted to Barcelona soil conditions. Technical Report. Barcelona: Institut Cartogràfic de Catalunya

Irizarry J (2004) An advanced approach to seismic risk assessment. Application to the cultural heritage and the urban system of Barcelona. Dissertation. Universidad Politécnica de Cataluña. Barcelona. Spain

Lagomarsino S, Cattari S (2009) Non linear seismic analysis of masonry buildings by the equivalent frame model. $11^{\circ}$ D-A-CH Conference: Masonry and earthquakes, Zurich, 10-11 September 2009, 85-100

Lagomarsino S, Giovinazzi S (2006) Macroseismic and mechanical models for the vulnerability and damage assessment of current buildings. Bulletin of Earthquake Engineering 4:415-443

Lagomarsino S, Galasco A, Penna A, Cattari S (2008) TREMURI: Seismic Analysis Program for 3D Masonry Buildings (User guide) Technical report. University of Genoa. Genoa (I)

Lantada N, Irizarry J $\cdot$ Barbat AH, Goula $\cdot$ X, R Roca A, S Susagna T, Pujades LG (2010) Seismic hazard and risk scenarios for Barcelona, Spain, using the Risk-UE vulnerability index method, Bulletin of Earthquake Engineering 8:201-229

Lantada N, Pujades LG, Barbat AH (2009) Vulnerability index and capacity spectrum based methods for urban seismic risk evaluation. A comparison. Natural Hazards 51:501-524

Lantada N (2007) Evaluación del riesgo sísmico mediante métodos avanzados y técnicas GIS. Aplicación a la ciudad de Barcelona. Dissertation. Universidad Politécnica de Cataluña, Barcelona, Spain.

Mari A, Alegre V, Gens A, Roca P (2003) Estudio preliminar sobre los posibles efectos de la construcción de un túnel para el tren de alta velocidad bajo los edificios situados entre las calles Mallorca, Valencia, Lepanto y Cartagena. Technical Report. Departamento de Ingeniería de la Construcción. Universidad Politécnica de Cataluña. Barcelona, Spain 
Milutinovic ZV, Trendafiloski GS (2003) WP4: Vulnerability of current buildings. Risk-UE project Handbook. September 2003. Risk-UE project report

Moreno R (2006) Evaluación del riesgo sísmico en edificios mediante análisis estático no lineal: aplicación a diversos escenarios sísmicos de Barcelona. Dissertation. Universidad Politécnica de Cataluña. Barcelona. Spain. http://www.tdx.cat/TDX-0702107-165654. Accessed 10 June 2010

Paricio A (2001) Secrets d' un sistema constructiu: l'Eixample. Edicions UPC, Barcelona.

Park J, Towashiraporn P, Craig JI, Goodno BJ (2009) Seismic fragility analysis of low-rise unreinforced masonry structures. Engineering Structures 31: 125-137

Penna A (2002) A macro-element procedure for the non-linear dynamic analysis of masonry buildings. Dissertation, Politécnico de Milano, Italy

Permanyer L (1990) Historia de l’Eixample. Ed Plaza y Janés. Barcelona, Spain

Ribas M (2004) Barcelona i la Catalunya-ciutat. Ed Angle. Barcelona. Spain

Solé L (1975) Geografia de Catalunya. Ed Aedos, Barcelona. Spain

Whitman RW (1973) Damage probability matrices for prototype buildings. Report R73-57, Massachusetts Institute of Technology. Department of Civil Engineering Research, Cambridge

Yépez F, Barbat AH Canas JA (1996) Simulación de escenarios del daño sísmico en zonas urbanas. Revista internacional de métodos numéricos para cálculo y diseño en ingeniería 12(3): 331-358 